\title{
The case for impact-focused environmental psychology
}

\author{
Kristian S. Nielsen \\ University of Cambridge \\ Viktoria Cologna \\ ETH Zürich \\ Florian Lange \\ KU Leuven \\ Cameron Brick \\ University of Amsterdam \\ Paul C. Stern
}

Social and Environmental Research Institute

* All authors contributed equally to this work.

In press 2021, Journal of Environmental Psychology

Postprint DOI 10.31234/osf.io/w39c5

CC BY-NC-ND

Please address correspondence concerning this article to:

Kristian Steensen Nielsen

Department of Zoology

University of Cambridge

Pembroke Street

CB2 3QZ Cambridge

United Kingdom

ksn27@cam.ac.uk 
Human activities are causing climate change and severely degrading ecosystems resulting in biodiversity loss unprecedented for millions of years (IPBES, 2019; IPCC, 2018). Mitigating these problems largely hinges on changing human behavior. Although a major stream of environmental psychology is interested in changing behavior to address environmental degradation, psychologists have not had much impact on global initiatives to mitigate biodiversity loss or climate change. This is exemplified by psychologists' growing but still limited representation in major research collaborations such as the Intergovernmental Panel on Climate Change (IPCC) and the Intergovernmental Science-Policy Platform on Biodiversity and Ecosystem Services (IPBES).

We argue that psychologists can increase their contribution to mitigating environmental degradation if they focus primarily on environmental impact and secondarily on psychological theory when setting research priorities. We do not question the value of theory within environmental psychology, and we recognize that psychological theory has made several important contributions in the past (some of which are reviewed below). Instead, we contend that prioritizing psychological theory leads to the systematic neglect of some particularly impactful behaviors and their determinants. This inattention to high-impact behavior is widely noted (Stern \& Gardner, 1981; Stern, 2000, 2011; Capstick, Lorenzoni, Corner, \& Whitmarsh, 2014; Maki, Burns, Ha, \& Rothman, 2016; Nielsen et al., 2020a; Whitmarsh, 2009), and it may make psychological findings appear irrelevant to other scientists and policymakers (Fischhoff, 2020; Nielsen et al., 2020a). In the following, we offer a brief analysis of this problem and a path towards more impactful psychological research agendas.

The prioritization of psychological theory is reflected in the widespread use of the concept of 'pro-environmental behavior' (PEB) and the use of multi-item scales for its measurement (see Lange \& Dewitte, 2019, for review). This concept focuses attention on psychological antecedents rather than environmental impact of behavior (Stern 2000). The use of PEB scales assumes that all the included behaviors are linked by a common psychological construct (e.g., environmental attitude, Kaiser, Byrka, \& Hartig, 2010). Research guided by the PEB construct tends to neglect environmentally important behaviors for which non-psychological determinants are critical and for which environmental attitude is only a weak predictor (Black et al., 1985). In particular, infrequent choices such as home and vehicle purchases, investments in solar panels, and decisions about family size have large environmental impacts (Dietz et al., 2009; Wynes \& Nicholas, 2017) and important non-attitudinal determinants (Wolske \& Stern, 2018). Such high-impact behaviors rarely appear on PEB scales, or if present are typically hypothetical.

Additionally, treating PEB as a behavioral class of common psychological origin may reinforce the idea that research findings can be generalized from one behavior to another. However, studies repeatedly show that psychological factors predictive of low-impact behaviors are much less so for behaviors of higher impact (e.g., van der Linden, 2018), for which contextual factors beyond the individual are usually of greater importance (Black, Stern, \& Elworth, 1985; Wolske \& Stern, 2018). Hence, we cannot expect insights from the study of low-impact behaviors to generalize to high-impact behaviors. As a result, high-impact behaviors are neither studied directly (e.g., because they do not fit into the theoretical needs of PEB scales) nor indirectly (e.g., because we cannot generalize from low-impact behaviors). Exclusive reliance on theory-driven PEB research may thus exclude key behaviors from scientific analysis and limit psychological research's policy applications. For increasing its practical impact, we suggest that environmental psychology would benefit from reallocating some of its resources to an inductive research approach that focuses on the environmental impact of behaviors first (e.g., Kraft-Todd et al., 2018; Nayum, Klöckner, \& Mehmetoglu, 2016). 


\section{An impact-focused research agenda}

In contrast to deductive approaches starting from common theories in environmental psychology, an impact-first approach selects behaviors with high potential impact, uses a behavior-specific analysis, and only then abstracts to other behaviors and theory building. We suggest these stages:

1. Impact. Identify behavior with high potential for impact on a specific environmental problem. Then address behavioral plasticity, that is, variation or change in the behavior (Dietz et al., 2009). Focus on the most impactful behavior, not only in people's consumption but also in their non-consumer roles including as citizens, investors, participants in organizations, and members of communities (Nielsen et al., 2020a).

2. Behavior mapping. Identify where and in which contexts the behavior occurs, how often, and by which actors. Elaborate or novel psychological theory is not necessary for this stage (see also Scheel, Tiokhin, Isager, \& Lakens, 2020).

3. Accumulate behavior-specific knowledge. Systematically examine the determinants of the selected behavior and evaluate interventions for their potential to change the behavior, not only proxies like attitudes or intentions.

4. Extend to other behaviors. Repeat 1-3 with other behaviors and contexts.

5. Synthesize and theorize. Integrate results across behaviors (e.g., via reviews or through an open-sourced database similar to the Human Behavior Change Project; www.humanbehaviourchange.org) to arrive at increasingly general principles for integrating behavioral with other influences on environmental impacts.

Focusing first on environmental impact holds great promise for increasing the practical relevance of psychology. An inductive impact-first approach means using the specific environmental problem to determine which behaviors should be analyzed. To identify target behaviors, psychologists can draw on well-established methods from environmental science such as life cycle assessment and ecological footprints (e.g., Ivanova et al. 2020). This ensures that highimpact behaviors cannot slip through the net for not meeting the assumptions of current PEB research. In contrast to research starting from psychological theory, an impact-first approach is also less selective in identifying potential determinants of behavior. Not being bound to a specific theoretical framework, this approach strives to identify the major causes of variation in target behaviors, including non-psychological and structural factors (e.g., laws, markets, or local infrastructure). This enables better communication with other fields (e.g., sociology, engineering, and public policy) and promotes more humility about the importance of current psychological theories for solving environmental problems.

For some behaviors, in some contexts, psychological factors alone will not be useful for changing high-impact behaviors. Importantly, this does not imply that an impact-first approach would dispense with theory. Rather than using theory deductively for the selection of target behaviors and determinants, theory emerges from and is refined by integrating findings across behaviors and contexts. This inductive process can provide a stronger empirical basis for generalizing across behaviors and it can reveal regularities of behavior change that may extend beyond the environmental domain, e.g., to health behaviors.

We acknowledge that the costs and difficulty of studying high-impact behaviors (e.g., infrequent investment decisions), as well as the pressures on researchers working within psychology departments may create barriers to the adoption of an inductive impact-first approach. Several means can overcome these difficulties. First, including the assessment of high-impact behaviors into large-scale panel studies (e.g., European Social Survey) may allow for the detection of change in low-frequency behaviors. Second, resources can be pooled in the context of cross-lab and 
interdisciplinary collaborations (e.g., the Psychological Science Accelerator; Moshontz et al., 2018). Finally, psychology journals can increasingly welcome reports of inductive, impact-driven research and psychologists can publish in journals focused on environmental issues but not tied to discipline-based approaches.

When putting impact first, environmental psychologists can earn an important role in addressing local, national, and global environmental problems, as well as in interdisciplinary and international research collaborations, which currently struggle to adequately incorporate behavioral factors (Beckage et al., 2020; Cinner, 2018; Nielsen et al. 2020b). An inductive approach focused on specific problems may make psychology's contributions more attractive for large research collaborations and funding agencies (e.g., EU Horizon 2020 grants). Most importantly, psychologists can rise to the historic occasion and promote more effective solutions to dire environmental problems.

\section{References}

Beckage, B., Lacasse, K., Winter, J. M., Gross, L. J., Fefferman, N., Hoffman, F. M., ... \& Kinzig, A. (2020). The Earth has humans, so why don't our climate models?. Climatic Change, 163, $181-188$.

Black, J.S., Stern, P.C., \& Elworth, J.T. (1985) Personal and contextual influences on household energy adaptations. Journal of Applied Psychology, 70, 3-21.

Capstick, S., Lorenzoni, I., Corner, A., \& Whitmarsh, L. (2014). Prospects for radical emissions reduction through behavior and lifestyle change. Carbon Management, 5, 429-445.

Cinner, J. (2018). How behavioral science can help conservation. Science, 362, 889-890.

Dietz, T., Gardner, G. T., Gilligan, J., Stern, P. C., \& Vandenbergh, M. P. (2009). Household actions can provide a behavioral wedge to rapidly reduce US carbon emissions. Proceedings of the National Academy of Sciences, 106, 18452-18456.

Fischhoff, B. (2020). Making behavioral science integral to climate science and action. Behavioural Public Policy, 1-15.

IPBES. (2019). Summary for policymakers of the global assessment report on biodiversity and ecosystem services of the Intergovernmental Science-Policy Platform on Biodiversity and Ecosystem Services (S. Díaz, J. Settele, E. S. Brondízio E.S., H. T. Ngo, M. Guèze, J. Agard, A. Arneth, P. Balvanera, K. A. Brauman, S. H. M. Butchart, K. M. A. Chan, L. A. Garibaldi, K. Ichii, J. Liu, S. M. Subramanian, G. F. Midgley, P. Miloslavich, Z. Molnár, D. Obura, ... C. N. Zayas (eds.)). IPBES secretariat.

IPCC. (2018). Summary for Policymakers. Special Report: Global Warming of $1.5^{\circ} \mathrm{C}$. In V. Masson-Delmotte, P. Zhai, H.-O. Pörtner, D. Roberts, J. Skea, P. R. Shukla, A. Pirani, W. Moufouma-Okia, C. Péan, R. Pidcock, S. Connors, J. B. R. Matthews, Y. Chen, X. Zhou, M. I. Gomis, E. Lonnoy, T. Maycock, M. Tignor, \& T. Waterfield (Eds.), Global Warming of $1.5^{\circ} \mathrm{C}$. An IPCC Special Report on the impacts of global warming of $1.5^{\circ} \mathrm{C}$ above preindustrial levels and related global greenhouse gas emission pathways, in the context of strengthening the global response to the threat of climate change, (p. 32). World Meteorological Organization. https://www.ipcc.ch/site/assets/uploads/sites/2/2019/05/SR15_SPM_version_report_LR.pdf

Ivanova, D., Barrett, J., Wiedenhofer, D., Macura, B., Callaghan, M., \& Creutzig, F. (2020). Quantifying the potential for climate change mitigation of consumption options. Environmental Research Letters, 15, 093001.

Kaiser, F. G., Byrka, K., \& Hartig, T. (2010). Reviving Campbell's paradigm for attitude research. Personality and Social Psychology Review, 14, 351-367. 
Kraft-Todd, G. T., Bollinger, B., Gillingham, K., Lamp, S., \& Rand, D. G. (2018). Credibilityenhancing displays promote the provision of non-normative public goods. Nature, 563, 245248.

Lange, F., \& Dewitte, S. (2019). Measuring pro-environmental behavior: Review and recommendations. Journal of Environmental Psychology, 63, 92-100.

Maki, A., Burns, R. J., Ha, L., \& Rothman, A. J. (2016). Paying people to protect the environment: A meta-analysis of financial incentive interventions to promote proenvironmental behaviors. Journal of Environmental Psychology, 47, 242-255.

Moshontz, H., Campbell, L., Ebersole, C. R., IJzerman, H., Urry, H. L., Forscher, P. S., ... \& Chartier, C. R. (2018). The Psychological Science Accelerator: Advancing psychology through a distributed collaborative network. Advances in Methods and Practices in Psychological Science, 1, 501-515.

Nayum, A., Klöckner, C. A., \& Mehmetoglu, M. (2016). Comparison of socio-psychological characteristics of conventional and battery electric car buyers. Travel Behaviour and Society, 3, 8-20.

Nielsen, K. S., Clayton, S., Stern, P. C., Dietz, T., Capstick, S., \& Whitmarsh, L. (2020a). How psychology can help limit climate change. American Psychologist.

Nielsen, K. S., Stern, P. C., Dietz, T., Gilligan, J. M., van Vuuren, D. P., Figueroa, M. J., ... \& Vandenbergh, M. P. (2020b). Improving Climate Change Mitigation Analysis: A Framework for Examining Feasibility. One Earth, 3, 325-336.

Scheel, A. M., Tiokhin, L., Isager, P. M., \& Lakens, D. (2020). Why hypothesis testers should spend less time testing hypotheses. Perspectives on Psychological Science, 1745691620966795.

Stern, P. C., \& Gardner, G. T. (1981). Psychological research and energy policy. American Psychologist, 36, 329-342.

Stern, P. C. (2000). Toward a coherent theory of environmentally significant behavior. Journal of Social Issues, 56, 407-424.

Stern, P.C. (2011). Contributions of psychology to limiting climate change. American Psychologist, 66, 303-314.

van der Linden, S. (2018). Warm glow is associated with low-but not high-cost sustainable behaviour. Nature Sustainability, 1, 28-30.

Whitmarsh, L. (2009). Behavioural responses to climate change: Asymmetry of intentions and impacts. Journal of Environmental Psychology, 29, 13-23.

Wolske, K. S., \& Stern, P. C. (2018). Contributions of psychology to limiting climate change: Opportunities through consumer behavior. In: Clayton, S., \& Manning, C. (Eds.). Psychology and climate change: human perceptions, impacts, and responses (pp. 127-160). Elsevier, Amsterdam.

Wynes, S., \& Nicholas, K. A. (2017). The climate mitigation gap: Education and government recommendations miss the most effective individual actions. Environmental Research Letters, 12, 074024. https://doi.org/10.1088/1748-9326/aa7541 